\title{
Nfatc1 Is a Functional Transcriptional Factor Mediating Nell-1-Induced Runx3 Upregulation in Chondrocytes
}

\author{
Chenshuang Li ${ }^{1,+}$, Zhong Zheng ${ }^{1,+}{ }^{(0)}$, Xinli Zhang ${ }^{1}$, Greg Asatrian ${ }^{1}$, Eric Chen ${ }^{1}$, \\ Richard Song ${ }^{1}$, Cymbeline Culiat ${ }^{2}$, Kang Ting ${ }^{1, *}$ and Chia Soo ${ }^{3, *}$ \\ 1 Division of Growth and Development, Section of Orthodontics, School of Dentistry, University of California, \\ Los Angeles, Los Angeles, CA 90095, USA; chenshuanglee@gmail.com (C.L.); \\ zzheng@dentistry.ucla.edu (Z.Z.); xinli@ucla.edu (X.Z.); gasatrian@ucla.edu (G.A.); \\ ericchenucla@g.ucla.edu (E.C.); richardsong227@gmail.com (R.S.) \\ 2 NellOne Therapeutics, Inc., 99 Midway Ln \# E, Oak Ridge, TN 37830, USA; cymbeline@nell-one.com \\ 3 Division of Plastic and Reconstructive Surgery and Department of Orthopaedic Surgery, the Orthopaedic \\ Hospital Research Center, University of California, Los Angeles, Los Angeles, CA 90095, USA \\ * Correspondence: kting@dentistry.ucla.edu (K.T.); bsoo@ucla.edu (C.S.); \\ Tel.: +1-310-206-6305 (K.T.); +1-310-794-5479 (C.S.) \\ + These authors contributed equally to this work.
}

Received: 4 December 2017; Accepted: 5 January 2018; Published: 6 January 2018

\begin{abstract}
Neural EGFL like 1 (Nell-1) is essential for chondrogenic differentiation, maturation, and regeneration. Our previous studies have demonstrated that Nell-1's pro-chondrogenic activities are predominantly reliant upon runt-related transcription factor 3 (Runx3)-mediated Indian hedgehog (Ihh) signaling. Here, we identify the nuclear factor of activated T-cells 1 (Nfatc1) as the key transcriptional factor mediating the Nell-1 $\rightarrow$ Runx3 signal transduction in chondrocytes. Using chromatin immunoprecipitation assay, we were able to determine that Nfatc1 binds to the $-833--810$ region of the Runx3-promoter in response to Nell-1 treatment. By revealing the Nell-1 $\rightarrow$ Nfatc $1 \rightarrow$ Runx $3 \rightarrow$ Ihh cascade, we demonstrate the involvement of Nfatc1, a nuclear factor of activated T-cells, in chondrogenesis, while providing innovative insights into developing a novel therapeutic strategy for cartilage regeneration and other chondrogenesis-related conditions.
\end{abstract}

Keywords: neural EGFL like 1 (Nell-1); nuclear factor of activated T-cells 1 (Nfatc1); runt-related transcription factor 3 (Runx3); chondrogenesis

\section{Introduction}

A diverse group of molecules is involved in the regulation of chondrogenic differentiation, an essential process for bone and cartilage formation [1]. Previous studies demonstrated that neural EGFL like 1 (Nell-1) enhanced chondrogenic marker expression and cartilage nodule formation in rabbit chondrocytes [2]. Additionally, Nell-1 administration has been observed to induced hyaline cartilage regeneration in a rabbit knee subchondral defect model [3], and implantation of Nell-1-overexpressing bone marrow mesenchymal stem cells into critical-sized goat mandibular condyle osteochondral defects resulted in articular cartilage reestablishment [4]. Conversely, homozygous $N$-ethyl- $N$-nitrosourea (ENU)-induced Nell-1-deficient mice fail to survive perinatally, accompanied by shorter and deformed rib cages and vertebral bodies, compressed intervertebral spaces, and reduced expression of cartilage matrix in comparison with those of the wild-type and heterozygous littermates [5]. Our recent studies demonstrated that, in chondrocytes, the expression of Nell-1 is regulated by the runt-related transcription factor 2 (Runx2) [6], a pivotal transcriptional 
factor regulating chondrogenesis [7]. Interestingly, Nell-1's pro-chondrogenic activities extended to Run $x 2^{-/-}$scenarios by stimulating the expression and signal transduction of runt-related transcription factor 3 (Runx3) and its downstream target Indian hedgehog (Ihh) [6,8].

Previous findings suggested that Runx3 is not one of the early response genes during Nell-1-regulated chondrogenesis [9]. As such, it is critical to identify the molecule(s) mediating the Nell-1-stimulated Runx3 expression to further elucidate the mechanism of action of Nell-1 in chondrogenesis. In this study, we first screened key transcriptional factors bridging the Nell- $1 \rightarrow$ Runx3 signal transduction using a two-step in silico promoter analysis and quantitative real-time PCR (qPCR) strategy. These findings were further validated using RNA interference (RNAi) technology. Subsequently, we used chromatin immunoprecipitation (ChIP) assay to recognize the binding site of the identified key Nell-1-induced transcriptional factor on the Runx3 promoter. The current study is not only an additional new section of a series of investigations that uncover the underlying mechanism of Nell-1's function in chondrogenesis, but also demonstrates the involvement of Nfatc1, a nuclear factor of activated T-cells, in chondrogenesis, while providing innovative insights that will assist in the development of a novel therapeutic strategy for cartilage regeneration and other chondrogenesis-related conditions.

\section{Results}

2.1. Runt-Related Transcription Factor 1 (Runx1) and Nfatc1 Were Selected as the Candidates That Bridge Nell-1 $\rightarrow$ Runx3 Signal Transduction in Chondrocytes

Using in silico bioinformatics software Genomatix to predict the binding candidates of mouse Runx 3 promoter, we identified 22 cartilage/chondrocyte-expressed transcriptional factor candidates (Table 1). Compared with previous microarray data that screened the primary response genes of Nell-1-mediated chondrogenesis (GEO DataSet: GSE23570) [9] as a reference, it was observed that runt-related transcription factor 1 (Runx1), T-cell leukemia, homeobox1 (Tlx1), nuclear factor of activated T-cells 1 (Nfatc1; previously known as nuclear factor of activated T-cells, cytoplasmic calcineurin-dependent 1 and also known as Nfat 2 and Nfatc), and nuclear factor of activated T-cells 5 (Nfat5) were significantly upregulated by Nell- 1 in chondrogenic-committed ATDC 5 cells and were therefore selected for further investigation in the current study. 
Table 1. Mouse Runx3 promoter binding transcriptional factor candidates that expressed in cartilage and chondrocytes.

\begin{tabular}{|c|c|c|c|c|c|c|c|}
\hline \multicolumn{2}{|c|}{ In Silico Bioinformatics Predicted } & \multicolumn{4}{|c|}{ Mouse Runx3 Promoter Binding Transcriptional Factors That Expressed in Cartilage and Chondrocytes } & \multicolumn{2}{|c|}{$\begin{array}{l}\text { Gene Expression Changes in ATDC } 5 \\
\text { Cells Due to the Nell-1 Treatment * }\end{array}$} \\
\hline Matrix Family & Gene & Full Name & Strand & Sequence $^{* *}$ & Matrix Similarity & Fold-Change & $p$-Value \\
\hline \multirow{5}{*}{ FKHD } & Foxp1 & Forkhead box P1 & $(-)$ & $5^{\prime}$-gggtcaaAACAgagggg-3' & 1 & 1.14 & $5.7 \times 10^{-6}$ \\
\hline & Foxp2 & Forkhead box P2 & $(+)$ & $5^{\prime}$-cagcagtaAACAgagag-3' & 0.994 & 0.79 & $1.1 \times 10^{-2}$ \\
\hline & Hnf3b/Foxa 2 & Hepatic nuclear factor 3 beta & $(+)$ & $5^{\prime}$-cagcagtaAACAgagag- $3^{\prime}$ & 0.914 & 0.32 & $2.0 \times 10^{-2}$ \\
\hline & Foxo1 & Forkhead box protein $\mathrm{O} 1$ & $(+)$ & $5^{\prime}$-aaaaagtcAACAcctcc- $3^{\prime}$ & 0.9 & 0.73 & $7.9 \times 10^{-5}$ \\
\hline & Fhx/Foxj2 & $\begin{array}{l}\text { Fork head homologous X binds DNA with a dual } \\
\text { sequence specificity (FHXA and FHXB) }\end{array}$ & $(+)$ & $5^{\prime}$-gtagccACAAgatcttc-3' & 0.835 & 0.84 & $2.6 \times 10^{-5}$ \\
\hline HAML & Runx1 & Runt-related transcription factor 1 & $(+)$ & $5^{\prime}$-ctgtGTGGtccggac-3' & 0.97 & 1.23 & $8.8 \times 10^{-5}$ \\
\hline \multirow{5}{*}{ HOMF } & Hhex & $\begin{array}{l}\text { Hematopoietically expressed homeobox, } \\
\text { proline-rich homeodomain protein }\end{array}$ & $\begin{array}{l}(+) \\
(+)\end{array}$ & $\begin{array}{l}5^{\prime} \text {-aactaggtgttTAATtttg- } 3^{\prime} \\
5^{\prime} \text {-ttcccaccattTAATgata- } 3^{\prime}\end{array}$ & $\begin{array}{l}0.969 \\
0.952\end{array}$ & 0.90 & $3.0 \times 10^{-4}$ \\
\hline & $H m x 3$ & $\begin{array}{l}\text { H6 homeodomain } \mathrm{HMX} 3 / \mathrm{Nkx} 5.1 \\
\text { transcription factor }\end{array}$ & $\begin{array}{l}(+) \\
(+) \\
(+)\end{array}$ & $\begin{array}{l}5^{\prime} \text {-cggaccccAAGTgcctcca-3' } \\
5^{\prime} \text {-ggctcaggAAGTgggggtg-3' } \\
5^{\prime} \text {-agccaaccAAGTgggtctg-3 }\end{array}$ & $\begin{array}{c}0.897 \\
0.911 \\
0.96\end{array}$ & 2.99 & $0.19^{* * *}$ \\
\hline & $M s x-1$ & Homeodomain proteins MSX-1 and MSX-2 & $(+)$ & $5^{\prime}$-aggtgttTAATtttgcaac- $3^{\prime}$ & 0.989 & 0.81 & $4.5 \times 10^{-4}$ \\
\hline & $H m x 2$ & Hmx2/Nkx5-2 homeodomain transcription factor & $(-)$ & $5^{\prime}$-gtatcaTTAAatggtggga-3' & 0.86 & 0.90 & $0.69^{* * *}$ \\
\hline & Tlx1/Hox11 & T-cell leukemia, homeobox 1 & $(-)$ & $5^{\prime}$-tgggagcCGCTgagtgggt-3' & 0.858 & 1.41 & $3.0 \times 10^{-2}$ \\
\hline \multirow[t]{2}{*}{ NFAT } & Nfatc1 & $\begin{array}{l}\text { Nuclear factor of activated T-cells, cytoplasmic, } \\
\text { calcineurin-dependent } 1 \text {, dimeric binding site }\end{array}$ & $\begin{array}{l}(-) \\
(+) \\
(-) \\
(+)\end{array}$ & $\begin{array}{l}5^{\prime} \text {-tttaccGTGGaacccagga-3' } \\
5^{\prime} \text {-ggttccACGGtaaagccag-3' } \\
5^{\prime} \text {-atctccAAGGaaagaaagt-3' } \\
5^{\prime} \text {-ctttccTTGGagattttct-3' }\end{array}$ & $\begin{array}{l}0.826 \\
0.816 \\
0.827 \\
0.877\end{array}$ & 1.55 & $5.3 \times 10^{-4}$ \\
\hline & Nfat5 & nuclear factor of activated T-cells 5 & $(-)$ & $5^{\prime}$-ccaaGGAAagaaagtttcg-3' & 0.844 & 1.52 & $6.0 \times 10^{-5}$ \\
\hline \multirow{4}{*}{ SORY } & Sox1 & $\begin{array}{l}\text { SRY (sex determining region Y)-box 1, dimeric } \\
\text { binding sites }\end{array}$ & $(-)$ & $5^{\prime}$-gctGATTccccactcaggcagag--3' & 0.795 & 0.43 & $0.14^{* * *}$ \\
\hline & Sox 21 & $\begin{array}{l}\text { SRY (sex determining region Y)-box 21, dimeric } \\
\text { binding sites }\end{array}$ & $\begin{array}{c}(-) \\
(+)\end{array}$ & $\begin{array}{l}5^{\prime} \text {-cctGCATgttggtcacacaacta-3' } \\
5^{\prime} \text {-attTAATgatactctgcacatag-3 } 3^{\prime}\end{array}$ & $\begin{array}{l}0.783 \\
0.762\end{array}$ & $\mathrm{ND}^{* * * *}$ & $\mathrm{ND}^{* * * *}$ \\
\hline & Sox 2 & SRY-box containing gene 2 , dimeric binding sites & $(-)$ & 5'-gatCAAGggtgtgaatagagtcc & 0.701 & 0.90 & $8.7 \times 10^{-6}$ \\
\hline & Sox8 & $\begin{array}{l}\text { SRY (sex determining region Y)-box 8, dimeric } \\
\text { binding sites }\end{array}$ & $\begin{array}{l}(-) \\
(+)\end{array}$ & $\begin{array}{l}5^{\prime} \text {-aatGAAAggcagtactgacctgc- } 3^{\prime} \\
5^{\prime} \text {-cagGACTcccagtctcacagggt- } 3^{\prime}\end{array}$ & $\begin{array}{l}0.777 \\
0.763\end{array}$ & $\mathrm{ND}^{* * * *}$ & $\mathrm{ND}^{* * * *}$ \\
\hline
\end{tabular}


Table 1. Cont.

\begin{tabular}{|c|c|c|c|c|c|c|c|}
\hline \multicolumn{2}{|c|}{ In Silico Bioinformatics Predicted } & \multicolumn{4}{|c|}{ Mouse Runx3 Promoter Binding Transcriptional Factors That Expressed in Cartilage and Chondrocytes } & \multicolumn{2}{|c|}{$\begin{array}{l}\text { Gene Expression Changes in ATDC5 } \\
\text { Cells Due to the Nell-1 Treatment * }\end{array}$} \\
\hline \multirow{4}{*}{ SORY } & Hbp1 & high mobility group box transcription factor 1 & $\begin{array}{l}(-) \\
(-) \\
(-) \\
(-)\end{array}$ & $\begin{array}{l}5^{\prime} \text {-aatgaatgAATGaacgaggctca-3' } \\
5^{\prime} \text {-gatgaatgAATGaatgaacgagg-3' } \\
5^{\prime} \text {-ctggatgAATGaatgaatgaacg-3' } \\
5^{\prime} \text {-cagctgGATGaatgaatgaatg- } 3^{\prime}\end{array}$ & $\begin{array}{c}1 \\
1 \\
0.996 \\
0.847\end{array}$ & 0.84 & $3.8 \times 10^{-5}$ \\
\hline & Sox 9 & SRY (sex determining region Y)-box 9 homodimer & $\begin{array}{l}(+) \\
(+) \\
(-)\end{array}$ & $\begin{array}{l}5^{\prime} \text {-acAGAAagcctaccttctctctc- } 3^{\prime} \\
5^{\prime} \text {-gaaccACAAggccaggccetcgc- } 3^{\prime} \\
5^{\prime} \text {-gcaCTATgtgcagagtatcatta- } 3^{\prime}\end{array}$ & $\begin{array}{l}0.787 \\
0.944 \\
0.733\end{array}$ & 0.76 & $1.1 \times 10^{-5}$ \\
\hline & Hmgiy/Hmga1 & $\begin{array}{l}\text { HMGI(Y) high-mobility-group protein I (Y), } \\
\text { architectural transcription factor organizing the } \\
\text { framework of a nuclear protein-DNA transcriptional } \\
\text { complex / High mobility group AT-Hook } 1\end{array}$ & $\begin{array}{l}(-) \\
(+)\end{array}$ & $\begin{array}{l}5^{\prime} \text {-cacaAATTttcaacagcactatg-3' } \\
5^{\prime} \text {-tgaaAATTtgtggctagacattc-3' }\end{array}$ & $\begin{array}{l}0.935 \\
0.935\end{array}$ & 0.56 & $1.5 \times 10^{-3}$ \\
\hline & Sox10 & SRY-box containing gene 10 & $(-)$ & 5'-caGGAAtgtctagccacaaattt-3' & 0.739 & 8.25 & $0.54^{* * *}$ \\
\hline PAX & $\operatorname{Pax} 1$ & $\begin{array}{l}\text { Pax1 paired domain protein, expressed in the } \\
\text { developing vertebral column of mouse embryos }\end{array}$ & $(-)$ & $5^{\prime}$-cTGTTttgttatatatatt-3' & 0.667 & $\mathrm{ND}^{* * * *}$ & $\mathrm{ND}^{* * * *}$ \\
\hline
\end{tabular}

${ }^{*}$ Data are subtracted from the GEO DataSet: GSE23570; ${ }^{* *}$ Capitalized characters represent the core sequence; ${ }^{* * *}$ Not statically significant; ${ }^{* * * *}$ Not detected in the published dataset $($ GEO DataSet: GSE23570) using Affymetrix Mouse Genome Array. 
Although preliminary microarray assay revealed that Nell-1 upregulated the expression of all four potential candidate genes [9], qPCR demonstrated that Nell-1 only significantly elevated Runx1 and Nfatc1 expression in ATDC5 cells (Figure 1a). To eliminate the influence of Runx2, which could significantly induce Nell-1 expression in chondrocytes [6] and stimulate their proliferation, differentiation, and hypertrophy [10-12], these four Nell-1-responsive transcriptional factor candidates were further validated in Run $x 2^{-/-}$chondrocytes [6,8]. Like in ATDC5 cells, Nell-1 did not alter Tlx1 expression in Run $x 2^{-/-}$chondrocytes (Figure 1b). Interestingly, in Run $x 2^{-/-}$chondrocytes, while only high dose Nell-1 slightly increased Runx1 and Nfat5, all tested doses of Nell-1 upregulated Nfatc1 expression significantly (Figure 1b). Moreover, the expression of Tlx1 and Nfat5 remained consistent in chondrocytes with different Nell-1 genotypes, while expression of Runx1 and Nfatc1 was significantly reduced in Nell-1 ${ }^{6 R / 6 R}$ chondrocytes (Figure 1c). Of the four tested transcriptional factor candidates, only $\mathrm{Nfatc1}$ was downregulated in $\mathrm{Nell}^{+/ 6 R}$ chondrocytes (Figure 1c), suggesting that $\mathrm{Nfatc1}$ is more sensitive to Nell-1 levels when compared to Runx1. Immunofluorescent (IF) staining confirmed a similar protein expression pattern of these candidates in the neonatal mouse femurs (Figure 2). Thus, Runx1 and Nfatc1 were selected for further investigation.
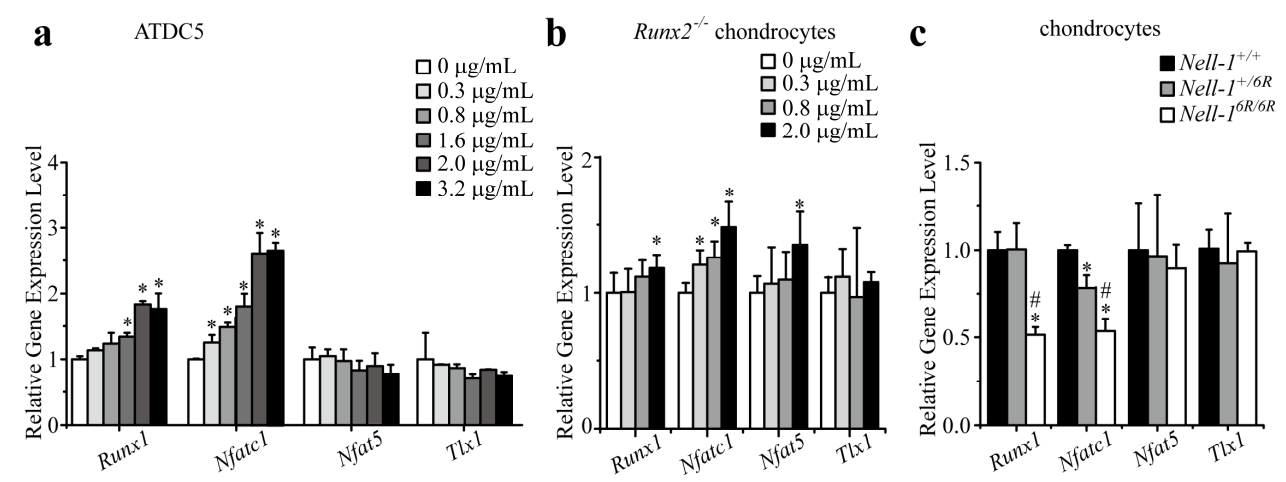

Figure 1. Nell-1 selectively alters the expression levels of Runx3-promoter binding candidates in chondrocytes. (a) Expression levels of Runx3-promoter binding candidates in monolayer cultured ATDC5 cells after stimulation with exogenous Nell-1 for $3 \mathrm{~h}$. * $p<0.05$ vs. $0 \mu \mathrm{g} / \mathrm{mL}$ Nell-1; (b) Expression levels of Runx3-promoter binding candidates in monolayer cultured Runx2-/- rib chondrocytes after stimulation with exogenous Nell-1 for $12 \mathrm{~h}$. * $p<0.05$ vs. $0 \mu \mathrm{g} / \mathrm{mL}$ Nell-1; (c) Expression levels of Runx3-promoter binding candidates in rib chondrocytes with different genotypes of Nell-1. *: $p<0.05$ vs. Nell- $1^{+/+}$chondrocytes; ${ }^{*}: p<0.05$ vs. Nell- $1^{+/ 6 R}$ chondrocytes. Mean $+\mathrm{SD}$ of three $(\mathbf{a}, \mathbf{b})$ or six $(\mathbf{c})$ independent experiments performed in triplicate are shown.

\subsection{Knockdown Runx1 Failed to Demonstrate the Effects on the Nell-1-Mediated Runx3-Ihh Signaling}

In the 2D monolayer-cultured Run $x 2^{-1-}$ chondrocytes, Runx1 knockdown by shRNA did not change the basal expression levels of Runx3, Acan (encoding aggrecan, a Runx3 downstream major structural component in cartilage matrix [7,13]), Ihh, Ptch1 (encoding Ihh downstream target patched homology 1 (Patched 1)), and Gli1 (encoding Ihh-responsive Gli1) (Figure 3a). Interestingly, Nell-1 significantly increased the expression of these genes in Runx1-knockdown Run $x 2^{-/-}$chondrocytes to levels comparable to that of the control shRNA $+2.0 \mu \mathrm{g} / \mathrm{mL}$ Nell-1 group (Figure 3a). Similar findings were observed in the 3D cultured Run $\times 2^{-/-}$chondrocyte micromass: the transcription of Runx3-related (Runx3 and Acan), Ihh signaling-related (Ihh and Ptch1), chondrogenic differentiation related genes Col2 $\alpha 1$ (encoding the $\alpha 1$ chain of type II collagen, an abundant and specific protein in cartilage [1,7]) and Sox 9 (encoding the master transcription factor for chondrogenesis initiation SRY-Box $9[1,7]$ ) (Figure 3b); also, Alcian Blue staining intensity (Figure 3c,d) was almost at the same levels as in the control shRNA $+0 \mu \mathrm{g} / \mathrm{mL}$ Nell-1 and Runx1 shRNA $+0 \mu \mathrm{g} / \mathrm{mL}$ Nell-1 groups. Furthermore, there were no significant differences observed between the control shRNA $+2.0 \mu \mathrm{g} / \mathrm{mL} \mathrm{Nell}-1$ and Runx 1 shRNA $+2.0 \mu \mathrm{g} / \mathrm{mL}$ Nell-1 groups with regard to these indexes (Figure $3 \mathrm{~b}-\mathrm{d}$ ). Thus, it can be 
concluded that Runx1 does not actively participate in the Nell-1 activation of Runx3-Ihh signaling in chondrocytes, at least when Runx2 is absent.
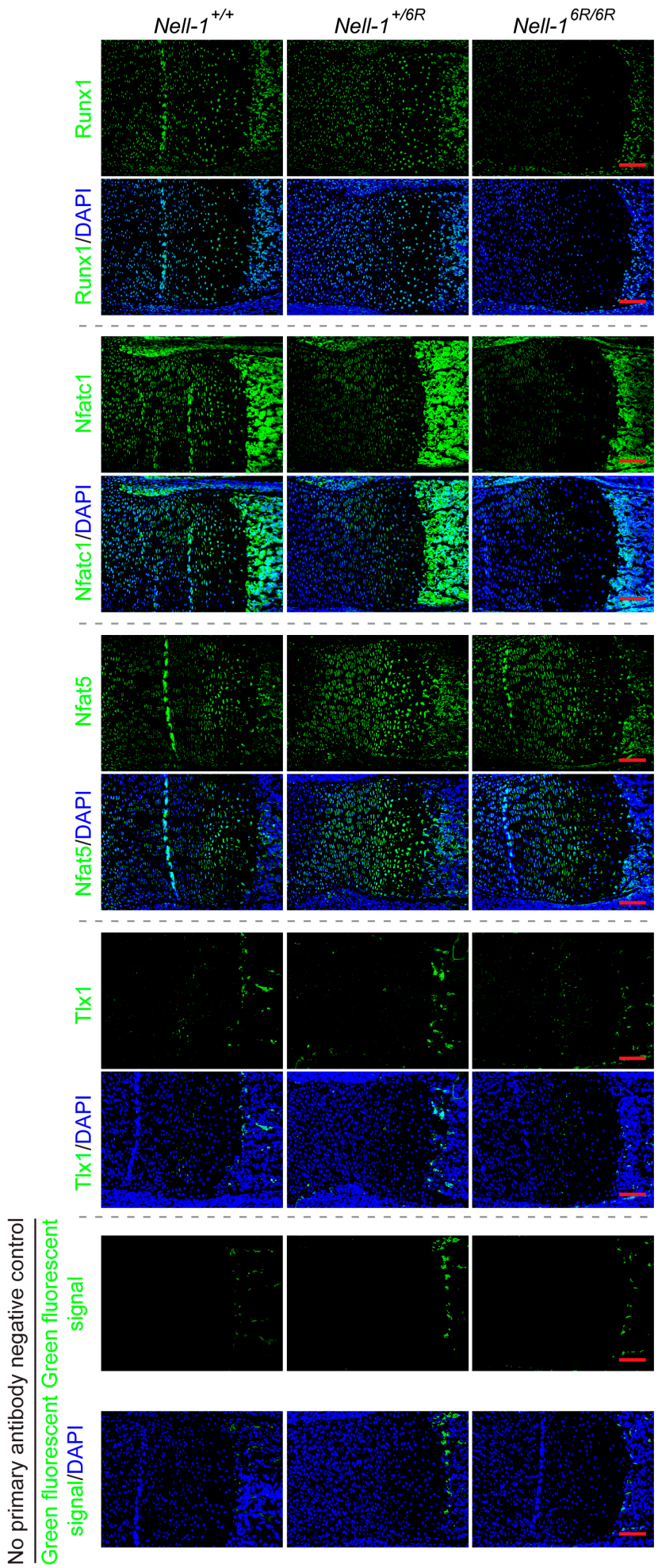

Figure 2. Immunofluorescent (IF) staining of Runx3-promoter binding transcriptional factor candidates in the femur of neonatal mice with different genotypes of Nell-1. Green, targeted molecule; blue, DAPI counterstaining. In the no primary antibody negative control, the green fluorescent signal was only detected on the red blood cells. Scale bar $=50 \mu \mathrm{m}$. 

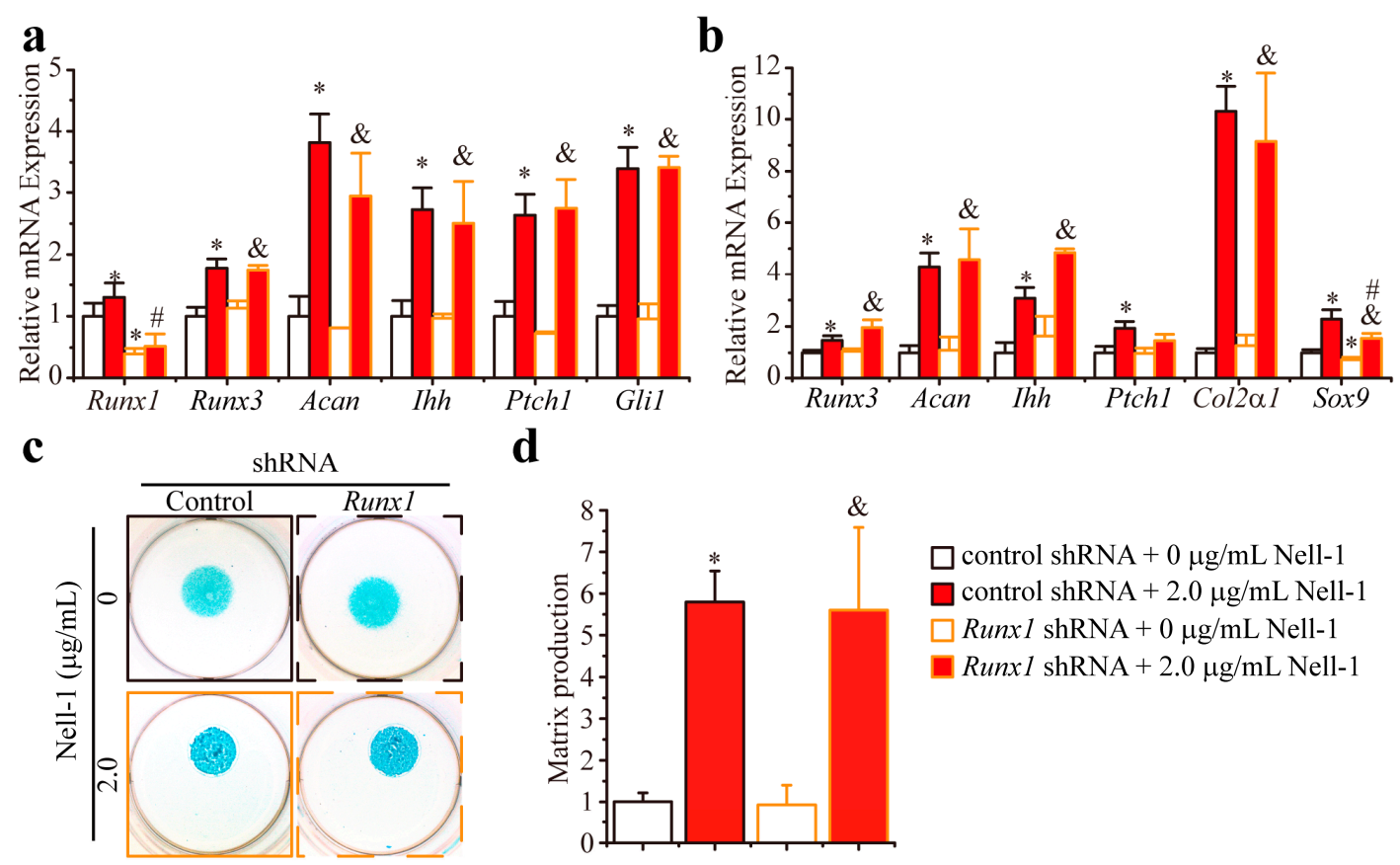

$\square$ control shRNA $+0 \mu \mathrm{g} / \mathrm{mL}$ Nell-1

$\square$ control shRNA $+2.0 \mu \mathrm{g} / \mathrm{mL}$ Nell-1

$\square$ Runxl shRNA $+0 \mu \mathrm{g} / \mathrm{mL}$ Nell-1

Q Runxl shRNA + $2.0 \mu \mathrm{g} / \mathrm{mL}$ Nell-1

Figure 3. Runx1 knockdown does not alter the Nell-1's effects on Runx3-Ihh signaling activation and chondrogenesis of Runx $2^{-/-}$rib chondrocytes. (a) Transcription of Runx3 and Ihh signal-related molecules in monolayer cultured $R u n \times 2^{-/-}$rib chondrocytes after 12-h stimulation of Nell-1; (b) Transcription of Runx3 and Ihh signal-related molecules in 3D micromass cultured Runx $2^{-/-}$ chondrocytes after 3-day stimulation of Nell-1; (c) Alcian Blue staining of 3D micromass cultured Run $\times 2^{-1-}$ chondrocytes after 3-day stimulation of Nell-1; (d) Alcian Blue incorporation into the extracellular matrix of micromass cultures reflecting the production of the proteoglycan-rich cartilaginous matrix at day 3 was quantified after extraction. The dye concentration of each group was normalized to that of the control shRNA $+0 \mu \mathrm{g} / \mathrm{mL}$ Nell-1 group. Mean + SD of three independent experiments performed in triplicate are shown. *: $p<0.05$ vs. control shRNA $+0 \mu \mathrm{g} / \mathrm{mL} \mathrm{Nell-1,}{ }^{*}$ : $p<0.05$ vs. control shRNA $+2.0 \mu \mathrm{g} / \mathrm{mL}$ Nell-1, $\&: p<0.05$ vs. Runx1 shRNA $+0 \mu \mathrm{g} / \mathrm{mL}$ Nell-1.

\subsection{Nfatc1 Mediates Nell-1's Role in Runx3-Ihh Signaling and Chondrogenic Differentiation}

Although $N f a t c 1$ knockdown by shRNA did not significantly alter the basal expression levels of either Runx 3 and its downstream target Acan, or of Ihh signaling-related genes (Ihh and Ptch1) in Run $\times 2^{-/-}$chondrocytes, Nell-1's stimulation of these genes was completely nullified by Nfatc1 knockdown (Figure 4a). Moreover, in the 3D cultured Run $x 2^{-/-}$chondrocyte micromass that underwent chondrogenic differentiation, Nell-1 was neither able to upregulate the expression of all tested genes or to enhance Alcian Blue staining in the Nfatc1-knockdown Run $x 2^{-/}$chondrocyte micromass (Figure $4 \mathrm{~b}-\mathrm{d}$ ). Importantly, when Nfatc1 was knocked down by shRNA transfection in Run $\times 2^{-/-}$chondrocytes, the expression of Sox 9 in the 3D cultured Run $x 2^{-/-}$chondrocyte micromass was significantly downregulated with or without the treatment of Nell-1, which indicates that the initiation of Nell-1-mediated chondrogenesis was blocked (Figure 4b). In aggregate, Nell-1's bioactivities on Runx3-Ihh signal activation and chondrogenic stimulation were abrogated by the Nfatc1 knockdown. 
a

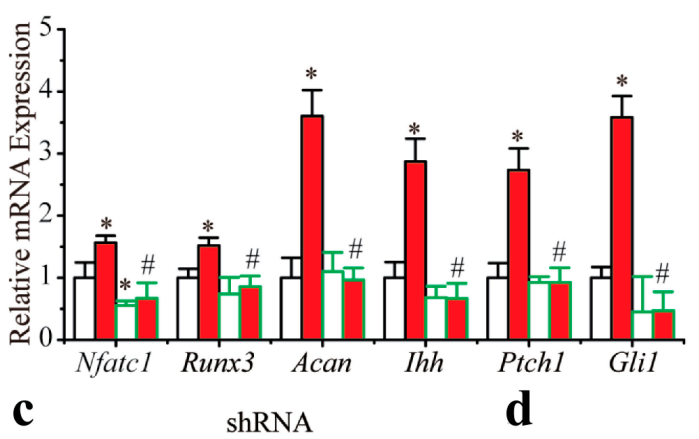

b

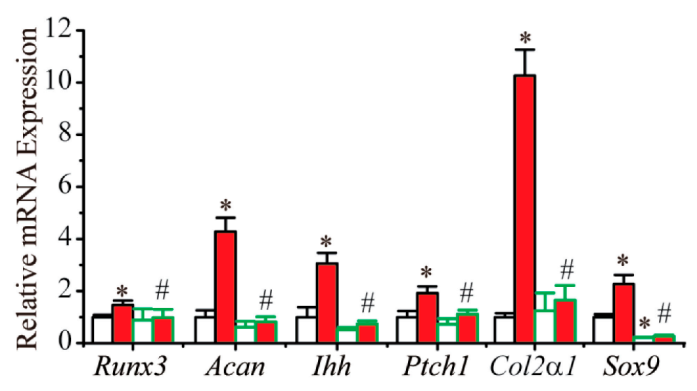

c

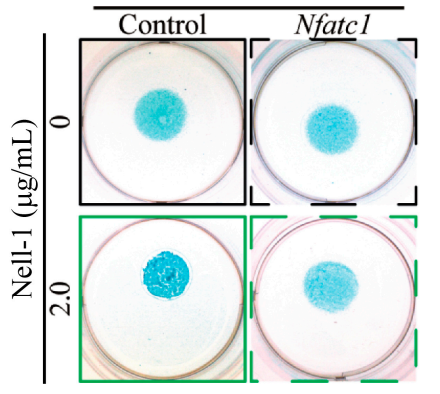

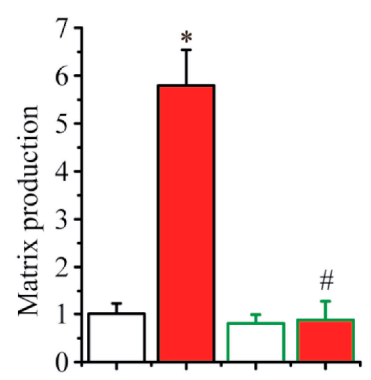

control shRNA $+0 \mu \mathrm{g} / \mathrm{mL}$ Nell-1

control shRNA $+2.0 \mu \mathrm{g} / \mathrm{mL}$ Nell-1

Nfatcl shRNA $+0 \mu \mathrm{g} / \mathrm{mL}$ Nell-1

Nfatcl shRNA $+2.0 \mu \mathrm{g} / \mathrm{mL}$ Nell-1

Figure 4. Nfatc1 is the bridging molecule between Nell-1 and the Runx3-Ihh signaling pathway in Run $x 2^{-/-}$rib chondrocytes. (a) Transcription of Runx3 and Ihh signal-related molecules in monolayer cultured Run $x 2^{-/-}$rib chondrocytes after 12-h stimulation of Nell-1; (b) Transcription of Runx3 and Ihh signal-related molecules in 3D micromass cultured Run $x 2^{-/-}$chondrocytes after 3-day stimulation of Nell-1; (c) Alcian Blue staining of 3D micromass cultured Run $x 2^{-/-}$chondrocytes after 3-day stimulation of Nell-1; (d) Alcian Blue incorporation into the extracellular matrix of micromass cultures reflecting the production of the proteoglycan-rich cartilaginous matrix at day 3 was quantified after extraction. The dye concentration of each group was normalized to that of the control shRNA +0 $\mu \mathrm{g} / \mathrm{mL}$ Nell-1 group. Mean $+\mathrm{SD}$ of three independent experiments performed in triplicate are shown. *: $p<0.05$ vs. control shRNA $+0 \mu \mathrm{g} / \mathrm{mL}$ Nell- $1,{ }^{\#}: p<0.05$ vs. control shRNA $+2.0 \mu \mathrm{g} / \mathrm{mL}$ Nell- 1 .

\subsection{Nell-1 Enhances the Binding of Nfatc1 at the -833--810 Region of Runx3 Promoter in Chondrocytes}

Based on the in silico findings, two potential binding sites of Nfatc1 were predicted on the promoter of Runx3: -280--257 (ACT TTC TTT CCT TGG AGA TTT TCT) and -833--810 (ACC TGG GTT CCA CGG TAA AGC CAG). Using both non-specific IgG and Nfatc1-specific antibody, ChIP assays were carried out. Negligible levels of DNA accumulation were observed at the $-280--257$ region, regardless of treatment with Nell-1 (Figure 5). Conversely, ChIP analysis using the Nfatc1-specific antibody demonstrated enrichment of the $-833--810$ fragment of the Runx3 promoter in Run $x 2^{-/-}$ chondrocytes, which was further enhanced by Nell-1 stimulation. Meanwhile, ChIP analysis using a negative control IgG demonstrated minimal enrichment of this DNA sequence with or without exogenous Nell-1 treatment (Figure 5). Therefore, our ChIP assays indicated that Nfatc1 binds to the $-833--810$ region of the Runx3-promoter in chondrocytes, and this binding is significantly enhanced by Nell-1. 


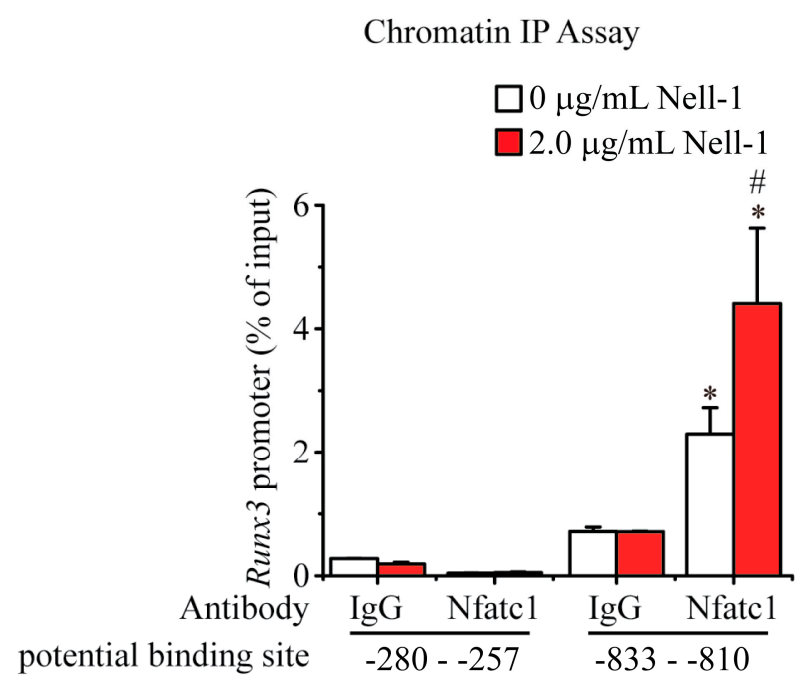

Figure 5. Nell-1 enhances the binding of Nfatc1 and Runx3-promoter in Run $x 2^{-/-}$rib chondrocytes. Chromatin Immunoprecipitation (ChIP) assay of Nfatc1's binding affinity to two potential binding sites on the Runx3 promoter was performed in Run $x 2^{-/-}$rib chondrocytes. * $p<0.05 \mathrm{vs}$. IgG $+0 \mu \mathrm{g} / \mathrm{mL}$ Nell-1, ${ }^{\#}: p<0.05$ vs. Nfatc1 antibody $+0 \mu \mathrm{g} / \mathrm{mL}$ Nell-1. Mean $+\mathrm{SD}$ of three independent experiments performed in triplicate are shown.

\section{Discussion}

Nearly two decades ago, Nell-1 was first observed to be upregulated in prematurely fusing and fused sutural sites of craniosynostosis (CS) patients [14], suggesting Nell-1's involvement in osteochondral development. Subsequently, our team has demonstrated that transgenic Nell-1overexpression (CMV-Nell-1) mice recapitulate human CS-like phenotypes [15,16]. On the other hand, homozygous Nell-1-deficient mice were noted to exhibit neonatal lethality with reduced calvarial bone thickness and density similar to those of calvarial cleidocraniodysplastic patients [5,17,18]. These phenomena strongly indicate that Nell-1 is pivotally involved in osteogenic development.

Nell-1 also exerts pro-chondrogenic bioactivities on both mesenchymal stem cells (MSCs) and chondrogenic-committed cells [6]. Until present, however, the function of Nell-1 in chondrogenesis has not attracted enough attention, and thus the mechanism of action of Nell-1 in chondrogenic differentiation remained largely elusive. Our recent studies have shown that Runx2 upregulates Nell-1 expression in chondrocytes, while Runx2-deficiency leads to significantly reduced Nell-1 levels, signifying that regulation of Runx2 has a profound impact on Nell-1 during chondrogenesis [6]. Unlike the mutual regulation between Nell-1 and Runx2 observed in osteoblast lineage cells [19-21], Nell-1 does not upregulate Runx2 in chondrocytes [6]. Further studies have also revealed that, as a downstream mediator of Runx2, Nell-1's pro-chondrogenic effect relies on the activation of Ihh signaling [8]. Unlike Runx2, however, which can directly bind to Ihh-promoter [10,22], Nell-1-mediated upregulation of Ihh signaling was under the control of Runx3 [8], and therefore Nell-1 is able to partially rescue Runx2-deficiency-induced impaired chondrogenic differentiation and maturation $[6,8]$.

In the current study, we have successfully identified and functionally validated Nfatc1 as the key transcriptional factor that bridges Nell-1 stimulation and Runx3 upregulation in chondrocytes. Nfatc1 functions as a key early Nell-1-response target in chondrocytes, upregulating Runx3 expression via binding to its promoter at $-833--810$ region and thus activating the Runx3-Ihh signal transduction cascade in order to induce chondrogenic differentiation and maturation (Figure 6). However, recent studies indicate that, as an 810-amino-acid secreted protein with multiple N-linked glycan chains, Nell-1 may function as oligomers [17]. Although the binding of Nell-1 with integrin $\beta 1$ has been detected previously [23,24], Nell-1's cell surface functional receptor(s) that initiates intracellular signal transduction, particularly in chondrogenic-committed cells, has yet to be discovered. Future studies 
through a global collaboration are warranted in order to gain a comprehensive understanding of the molecular mechanisms, especially the details of how Nell-1 stimulates Nfatc1 expression and modulates its activity. Nevertheless, the previously unrecognized Nell-1 $\rightarrow$ Nfatc $1 \rightarrow$ Runx3 $\rightarrow$ Ihh cascade provides innovative insights into developing a novel, therapeutic platform for managing cartilage regeneration and other chondrogenesis-related conditions.

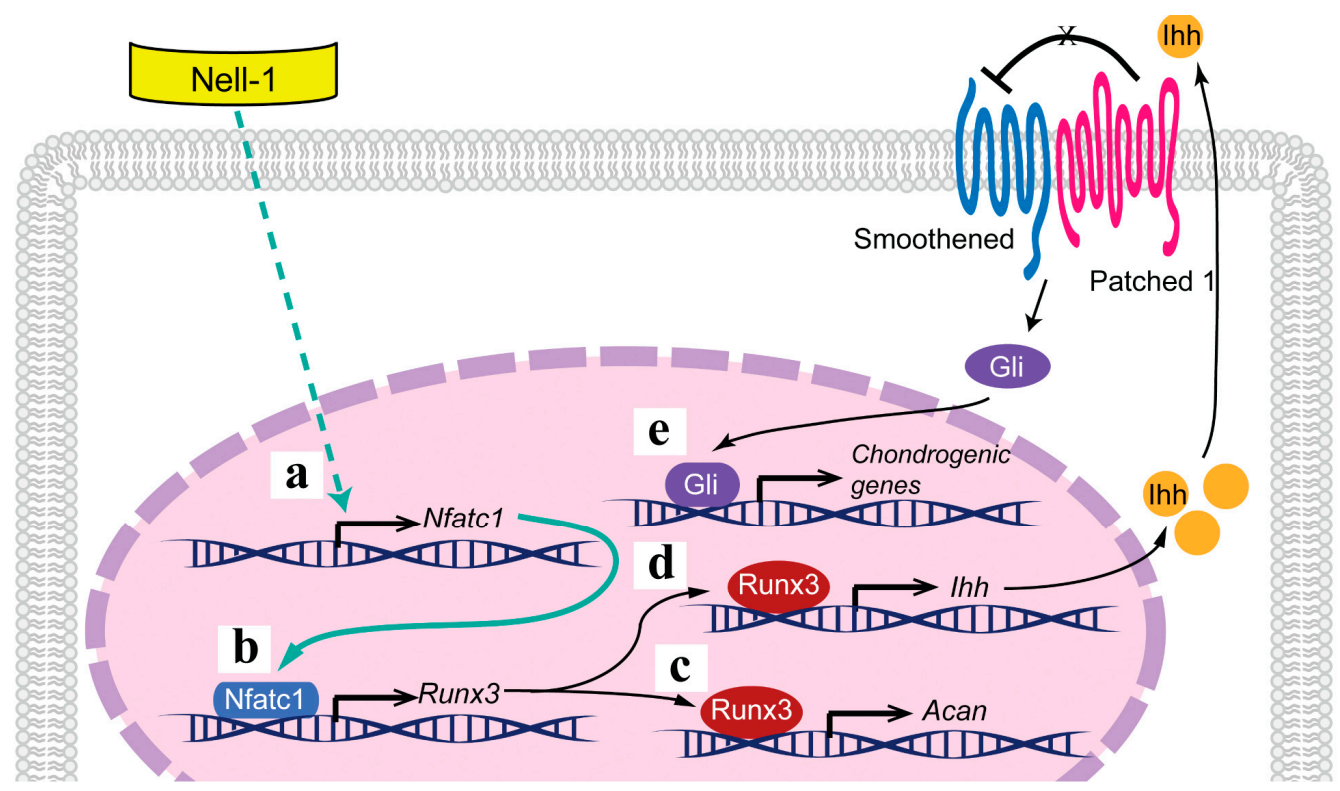

Figure 6. Schematic diagram of Nell-1 signaling pathways during chondrogenesis. (a) Nell-1 promotes Nfatc1 expression; (b) Nfatc1 next binds to the promoter of Runx3, activating the Runx3 signal transduction (c) as well as the Ihh signal transduction (d) to stimulate the differentiation and maturation of chondrocytes (e). Black arrows, previously revealed knowledge; green solid arrow, current uncovered regulation mechanism; green dashed arrow, a current suggested regulation mechanism which needs further investigation; T bar, known inhibitory effect.

Although Nfatc1-4 are all expressed in murine chondrocytes, only the regulatory effects of Nfatc1 and Nfatc2 on chondrogenesis were evaluated [25-27]. Since in silico predictions did not find the potential binding site of Nfatc 2 on Runx 3 promoter, Nfatc2 was not further investigated in this study. In 2010, Sohn et al. detected the expression of Nfatc1 in the intervertebral disc of E12.5-day old mice embryos and concluded this expression was upregulated by transforming growth factor $\beta 1$, but not bone morphogenetic protein 4, in sclerotome micromass culture [28]. In 2013, Zanotti and Canalis pioneered the investigation of Nfatc1's function during chondrogenesis by demonstrating that forcing overexpression of Nfatc 1 in mouse primary chondrocytes reduced the expression of Sox 9 and Col2 $\alpha 1$ at day 3 and Col10 $\alpha 1$ (encoding the $\alpha 1$ chain of type X collagen) expression at day 21 [29]. Moreover, Ge et al. revealed that Nfatc1 restricts the proliferation and chondrogenesis of osteochondroma precursors [30]. Although there is no significant difference reported between Nfatc1-mutant and wild-type mice during normal cartilage development or in the post-traumatic osteoarthritis animal model, cartilage-specific ablation of $\mathrm{Nfatc1}$ in $\mathrm{Nfatc}^{-/-}$mice markedly accelerated osteoarthritis development [31], which indicates that Nfatc1 may act as an osteoarthritis-suppressor. This study is the first report that clearly demonstrates the essential pro-chondrogenic role of Nfatc1 in mouse primary chondrocytes and reveals the potential underlying mechanism. In supporting the current understanding that "NFATs are good for your cartilage!" [32], our current discovery highlights the essential modulatory nature of Nfatc1 beyond its function as a regulator of inflammation [33] and enriches our knowledge about the myriad of complex interactions among a diverse group of growth factors and transcriptional factors during chondrogenesis. 


\section{Materials and Methods}

\subsection{In Silico Promoter Analysis}

Genomatix software suite v3.4 (Genomatix AG, Munich, Germany) was used to predict transcriptional factor binding motifs on the Runx3 promoter. Sites were computationally projected with predefined transcription factor binding modules [34] in the Promoter Module Library (Genomatix).

\subsection{Animal Maintenance}

Mice were bred and maintained as previously described $[5,15,20,35]$ under institutionally approved protocol provided by the Chancellor's Animal Research Committee at UCLA (protocol

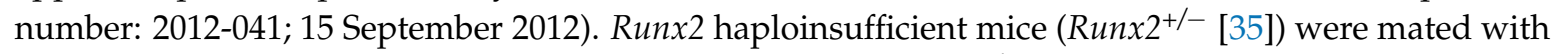
Nell-1-overexpressing mice (CMV-Nell-1 [15]) to obtain Run $x 2^{-/-} / C M V-N e l l-1$ mice [20]. Due to the severe reduction of Nell-1 expression in homozygotes (Nell-1 ${ }^{6 R / 6 R} ; \mathrm{Nell}-1^{6 R}$ : an ENU-induced point mutation truncating an 810 amino-acid Nell-1 protein at residue no. 502 [36,37]), neonatal death was induced [5]. Heterozygous Nell-1 ${ }^{6 R}$ mice $\left(N e l l-1^{+/ 6 R}\right)$ were used to produce Nell-1 $1^{6 R / 6 R}$ fetuses. Mouse genotypes were determined by PCR $[5,15,20,35]$.

\subsection{Immunofluorescence (IF) Staining}

Animals used in this study were euthanized via phenobarbital (Piramal Healthcare, Maharashtra, India) overdose. Hind limbs, isolated from neonatal mice, were fixed in $4 \%$ paraformaldehyde at $4{ }^{\circ} \mathrm{C}$ overnight before paraffin embedding and sectioning at $5-\mu \mathrm{m}$. IF staining was performed following the instruction of "abcam protocol book" (Abcam, available at http:// docs.abcam.com/pdf/misc/abcamprotocols-book-2010.pdf). All primary antibodies were purchased from Abcam (Cambridge, MA, USA), IHC-Tek ${ }^{\text {TM }}$ Antibody Diluent pH7.4 (IHCWORD, Woodstock, MD, USA) and were used for blocking and antibody dilution; Dnk pAb to Rb IgG (Alexa Fluor ${ }^{\circledR} 488$ ) (ab150073, Abcam) was used as the second antibody and 2-(4-amidinophenyl)-1H-indole-6-carboxamidine (DAPI; Sigma-Aldrich, St. Louis, MO, USA) was used for nuclear counterstaining.

\subsection{Cultivation of ATDC5 Cell Line}

A well-known chondrogenic-committed cell line, ATDC5 [38], was firstly used for the candidate transcriptional factor screening. ATDC5 cells were obtained from the RIKEN Cell Bank (Tsukuba, Japan) and cultured in ATDC maintenance medium composed of a 1:1 mixture of Dulbecco's modified Eagle's medium (DMEM) and Ham's F-12 medium containing $5 \%$ fetal bovine serum (FBS), $10 \mathrm{mg} / \mathrm{mL}$ of human transferrin (Sigma-Aldrich, St. Louis, MO, USA), and $30 \mathrm{nM}$ sodium selenite (Sigma-Aldrich) at $37^{\circ} \mathrm{C}$ in a humidified atmosphere consisting of $5 \% \mathrm{CO}_{2}$ and $95 \%$ air. All cell culture media were purchased from Invitrogen (Carlsbad, CA, USA). Subconfluent ATDC 5 cells were subjected to serum starvation $(0.1 \%$ FBS $)$ for 18 hours and stimulated with recombinant human Nell-1 protein for $3 \mathrm{~h}$ as previously described [8].

\subsection{Mouse Primary Chondrocyte Isolation and Cultivation}

Mouse primary chondrocyte isolation was conducted following the protocol provided by Dr. Karen Lyons' lab at UCLA, which is available at: https:/ / www.mcdb.ucla.edu/Research/Lyons/ Protocols_files/Isolation_of_Sternal_Chondrocytes.pdf. Briefly, after removing soft tissues with $2 \mathrm{mg} / \mathrm{mL}$ protease (Roche, Nutley, NJ, USA) in PBS and $3 \mathrm{mg} / \mathrm{mL}$ collagenase II (Roche) in DMEM, rib cages of neonatal mouse embryos were incubated in $1 \mathrm{mg} / \mathrm{mL}$ collagenase II for $3 \mathrm{~h}$ to achieve single-cell suspension. After rinsing with DMEM, chondrocytes were cultured in a basal culture medium (DMEM with 10\% FBS, $100 \mathrm{U} / \mathrm{mL}$ penicillin, and $100 \mu \mathrm{g} / \mathrm{mL}$ streptomycin). The medium was changed every 3 days and cells were passaged at $70-90 \%$ confluence $[6,8]$. 
$5 \times 10^{4}$ cells/well P2 chondrocytes were seeded in 6-well plates with basal culture medium for $6 \mathrm{~h}$. Recombinant human Nell-1 protein was synthesized by Aragen Bioscience Inc. (Morgan Hill, CA, USA) with a purity of $92 \%$. Before treatment, cells were synchronized by being cultured in a starvation medium (DMEM + 1\% ITS Universal Cell Culture Supplement Premix (BD Biosciences, San Jose, CA, USA)) for $18 \mathrm{~h}[6,8]$.

For 3D micromass culture, cells were reconstituted in the culture medium at a density of $1 \times$ $10^{7}$ cells $/ \mathrm{mL}$, and $10 \mu \mathrm{L}$ of cell suspension was dropped into each well of a 24 -well plate. The cell culture plates were incubated in a $37^{\circ} \mathrm{C}$ incubator for $3 \mathrm{~h}$ before adding culture medium to allow cells to attach to the dish $[6,8]$.

\subsection{RNAi}

Plasmid packages harboring shRNA targeting mouse Nfatc1 and Runx1, respectively, were obtained from Origene (Rockville, MD, USA). For each package, there were four shRNA plasmids harboring different sequences against the target genes. P2 chondrocytes isolated from Run $x 2^{-/}$mice were transfected with the shRNA plasmid with Lipofectamine 3000 reagent (Invitrogen). A control shRNA plasmid provided by OriGene was also used to transfect Run $x 2^{-/-}$mouse chondrocytes. Transfection efficiency was determined by qPCR.

\subsection{ChIP Assay}

ChIP assay was performed by using the Pierce Magnetic ChIP Kit (Thermo Fisher Scientific Inc., Waltham, MA, USA) following the manufacturer's instruction. $4 \times 10^{6} \mathrm{Run} \times 2^{-/-}$chondrocytes were used per ChIP reaction. After being synchronized in the starvation medium for $18 \mathrm{~h}$, cells were treated with Nell-1 for $12 \mathrm{~h} .5 \mu \mathrm{g}$ of a ChIP grade Nfatc1 primary antibody (Thermo Fisher Scientific Inc.) was used for each target-specific IP. qPCR analysis was performed to qualify the DNA fragments pulled down by antibodies. The primer sequences used are: $-833--810$ locus: Forward: $5^{\prime}$-CTGGGG AAG AGT CAG CAG GTC A-3', Reverse: 5'-GTG GAT CTG GCT TTA CCG TGG A-3'; -280--257 locus: Forward: 5'-TGT GGG ACT GGG AAG CCA AAT-3' ${ }^{\prime}$, Reverse: $5^{\prime}$-GGG AAA GAA CGC GAG AGC GT-3'.

\section{8. $q P C R$}

Total RNA was isolated by TRIzol ${ }^{\circledR}$ Reagent (Invitrogen) followed by DNase (Invitrogen) treatment. $1 \mu \mathrm{g}$ RNA was injected for reverse transcription (RT) with the SuperScript II Reverse Transcriptase Kit (Invitrogen). qPCR was performed on the 7300 Real-Time PCR system with SYBR Green Mastermix (Invitrogen). All the primer sequences used are listed in Table 2. Concomitant glyceraldehyde 3-phosphate dehydrogenase (Gapdh) was also evaluated in separate tubes for each RT reaction as a housekeeping standard. Relative gene expression was analyzed by ${ }_{\Delta \Delta} C_{T}$ method [39].

Table 2. Primer sequences used for real-time PCR.

\begin{tabular}{|c|c|}
\hline Gene & Primer Sequence \\
\hline Acan & $\begin{array}{l}\text { 5'-CCA GGC TCC ACC AGA TAC TC-3' } \\
5^{\prime} \text {-TGC TCA TAG CCT GCC TCA TA-3' }\end{array}$ \\
\hline Col $2 \alpha 1$ & $\begin{array}{l}5^{\prime} \text {-GTC CTG AAG GTG CTC AAG GT-3' } \\
5^{\prime} \text {-TTT GGC TCC AGG AAT ACC AT-3' }\end{array}$ \\
\hline Gapdh & $\begin{array}{l}\text { 5'-ATT CAA CGG CAC AGT CAA GG-3' } \\
5^{\prime} \text {-GAT GTT AGT GGG GTC TCG CTC-3' }\end{array}$ \\
\hline Gli1 & $\begin{array}{l}5^{\prime} \text {-CCA AGC CAA CTT TAT GTC AGG G-3' } \\
5^{\prime}-\text { AGC CCG CTT CTT TGT TAA TTT GA-3' }\end{array}$ \\
\hline
\end{tabular}


Table 2. Cont.

\begin{tabular}{|c|c|}
\hline Gene & Primer Sequence \\
\hline Ihh & $\begin{array}{l}5^{\prime} \text {-CTC AGA CCG TGA CCG AAA TAA G-3' } \\
5^{\prime} \text {-CCT TGG ACT CGT AAT ACA CCC AG-3' }\end{array}$ \\
\hline Nfat5 & $\begin{array}{l}\text { 5'-TGC TTT CTC AGC TTA CCA CGG-3' } \\
5^{\prime} \text {-GTC CGC ACA ACA TAG GGC TC-3' }\end{array}$ \\
\hline Nfatc1 & $\begin{array}{l}\text { 5'-GGA GAG TCC GAG AAT CGA GAT-3' }^{\prime} \\
5^{\prime} \text {-TTG CAG CTA GGA AGT ACG TCT-3' }\end{array}$ \\
\hline Ptch 1 & $\begin{array}{l}\text { 5'-TGC CAC AGC CCC TAA CAA AAA-3' } \\
5^{\prime} \text {-ACC CAC AAT CAA CTC CTC CTG-3' }\end{array}$ \\
\hline Runx1 & $\begin{array}{l}5^{\prime} \text {-ACG ATG AAA ACT ACT CGG CAG-3' } \\
5^{\prime} \text {-CTG AGG TCG TTG AAT CTC GCT-3' }\end{array}$ \\
\hline Runx 3 & $\begin{array}{l}\text { 5'-CAG GTT CAA CGA CCT TCG ATT-3' } \\
5^{\prime} \text {-GTG GTA GGT AGC CAC TTG GG-3' }\end{array}$ \\
\hline Sox 9 & $\begin{array}{l}\text { 5'-ACG GCT CCA GCA AGA ACA AG-3' } \\
5^{\prime} \text {-TTG TGC AGA TGC GGG TAC TG-3' }\end{array}$ \\
\hline$T l x 1$ & $\begin{array}{l}5^{\prime} \text {-CGG CTT GCC TAC AGT ACC C-3' } \\
5^{\prime} \text {-CTG CGG TTA CTC TCC ATC CAG-3' }\end{array}$ \\
\hline
\end{tabular}

\subsection{Alcian Blue Staining and Quantification}

Alcian Blue staining was performed by fixing micromass cultures at day 3 and then incubating them with $0.1 \%$ Alcian Blue, $\mathrm{pH} 2.5$, for $2 \mathrm{~h}$. Quantification of the staining was achieved after extensive washing with water by extraction with $6 \mathrm{M}$ guanidine-hydrogen chloride for $8 \mathrm{~h}$ at room temperature. All chemicals were purchased from Sigma-Aldrich (St. Louis, MO, USA). Dye concentrations were determined spectrophotometrically at $\mathrm{A}_{630}$ [40].

\subsection{Statistical Analysis}

All statistical analyses were conducted in consultation with the UCLA Statistical Biomathematical Consulting Clinic. ANOVA and two-sample $t$-tests were computed by OriginPro 8 (Origin Lab Corp., Northampton, MA, USA) for statistical analysis. $p$-Value $<0.05$ was considered statistically significant.

\section{Conclusions}

In this study, we identified and functionally validated Nfatc1 as a key transcriptional factor mediating Nell- $1 \rightarrow$ Runx3 signal transduction in chondrocytes by binding to the $-833--810$ region of Runx3-promoter. It is the first report that clearly demonstrates the essential pro-chondrogenic role of Nfatc1 in mouse primary chondrocytes and reveals the potential underlying mechanism. As an additional section of a series of investigations that uncover the underlying mechanism of Nell-1's function in chondrogenesis, this study provides innovative insights into developing a novel therapeutic platform for managing cartilage regeneration and other chondrogenesis-related conditions.

Acknowledgments: We would like to thank Wenfang Wang and Bjorn R. Olsen at Harvard University for providing the Run $x 2^{+/-}$mouse. This study was financially supported by NIH-NIAMS (grants R01AR066782, R01AR068835, R01AR061399), UCLA/NIH CTSI grant UL1TR000124, and National Aeronautical and Space Administration ("NASA") GA-2014-154. The content is solely the responsibility of the authors and does not necessarily represent the official views of the funding agencies.

Author Contributions: Kang Ting and Chia Soo conceived and supervised the study; Chenshuang Li, Zhong Zheng, and Xinli Zhang designed experiments; Chenshuang Li and Zhong Zheng performed experiments; Chenshuang Li, Zhong Zheng, and Xinli Zhang analyzed data; Cymbeline Culiat provided homozygous $\mathrm{N}$-ethyl- $\mathrm{N}$-nitrosourea (ENU)-induced Nell-1-deficient mice; Chenshuang Li and Zhong Zheng wrote the manuscript; Greg Asatrian, Eric Chen, and Richard Song made manuscript revisions. 
Conflicts of Interest: Xinli Zhang, Kang Ting, and Chia Soo are inventors of Nell-1 related patents and founders and/or past board members of Bone Biologics Inc./Bone Biologics Corp., who sublicense Nell-1 patents from the UC Regents, who also hold equity in the company. Cymbeline Culiat is an inventor of Nell-1 related patents filed from Oak Ridge National Laboratory (ORNL) and a founder of NellOne Therapeutics, Inc. which licensed Nell-1 related patent applications from ORNL. Bone Biologics Inc./Bone Biologics Corp. and NellOne Therapeutic, Inc. did not provide financial support for the current study. All the other authors declare no conflict of interest.

$\begin{array}{ll}\text { Abbreviations } \\ \text { Acan } & \text { Aggrecan } \\ \text { ChIP } & \text { Chromatin immunoprecipitation } \\ \text { DAPI } & \text { 2-(4-amidinophenyl)-1H-indole-6-carboxamidine } \\ \text { DMEM } & \text { Dulbecco's modified Eagle's medium } \\ \text { ENU } & \text { N-ethyl-N-nitrosourea } \\ \text { FBS } & \text { Fetal bovine serum } \\ \text { Gapdh } & \text { Glyceraldehyde 3-phosphate dehydrogenase } \\ \text { IF } & \text { Immunofluorescent } \\ \text { Ihh } & \text { Indian hedgehog } \\ \text { Nfat5 } & \text { Nuclear factor of activated T-cells 5 } \\ \text { Nfatc1 } & \text { Nuclear factor of activated T-cells 1 } \\ \text { Patched1 } & \text { Patched homology 1 } \\ \text { qPCR } & \text { Quantitative real-time PCR } \\ \text { RNAi } & \text { RNA interference } \\ \text { RT } & \text { Reverse transcription } \\ \text { Runx1 } & \text { Runt-related transcription factor 1 } \\ \text { Runx2 } & \text { Runt-related transcription factor 2 } \\ \text { Runx3 } & \text { Runt-related transcription factor 3 } \\ \text { Tlx1 } & \text { T-cell leukemia, homeobox1 } \\ & \end{array}$

\section{References}

1. Liu, C.F.; Samsa, W.E.; Zhou, G.; Lefebvre, V. Transcriptional control of chondrocyte specification and differentiation. Semin. Cell Dev. Biol. 2017, 62, 34-49. [CrossRef] [PubMed]

2. Lee, M.; Siu, R.K.; Ting, K.; Wu, B.M. Effect of Nell-1 delivery on chondrocyte proliferation and cartilaginous extracellular matrix deposition. Tissue Eng. Part A 2010, 16, 1791-1800. [CrossRef] [PubMed]

3. Siu, R.K.; Zara, J.N.; Hou, Y.; James, A.W.; Kwak, J.; Zhang, X.; Ting, K.; Wu, B.M.; Soo, C.; Lee, M. Nell-1 promotes cartilage regeneration in an in vivo rabbit model. Tissue Eng. Part A 2012, 18, 252-261. [CrossRef] [PubMed]

4. Zhu, S.; Zhang, B.; Man, C.; Ma, Y.; Hu, J. NEL-like molecule-1-modified bone marrow mesenchymal stem cells / poly lactic-co-glycolic acid composite improves repair of large osteochondral defects in mandibular condyle. Osteoarthr. Cartil. 2011, 19, 743-750. [CrossRef] [PubMed]

5. Desai, J.; Shannon, M.E.; Johnson, M.D.; Ruff, D.W.; Hughes, L.A.; Kerley, M.K.; Carpenter, D.A.; Johnson, D.K.; Rinchik, E.M.; Culiat, C.T. Nell1-deficient mice have reduced expression of extracellular matrix proteins causing cranial and vertebral defects. Hum. Mol. Genet. 2006, 15, 1329-1341. [CrossRef] [PubMed]

6. Li, C.; Jiang, J.; Zheng, Z.; Lee, K.S.; Zhou, Y.; Chen, E.; Culiat, C.T.; Qiao, Y.; Chen, X.; Ting, K.; et al. Neural EGFL-like 1 is a downstream regulator of runt-related transcription factor 2 in chondrogenic differentiation and maturation. Am. J. Pathol. 2017, 183, 963-972. [CrossRef] [PubMed]

7. Goldring, M.B. Chondrogenesis, chondrocyte differentiation, and articular cartilage metabolism in health and osteoarthritis. Ther. Adv. Musculoskelet. Dis. 2012, 4, 269-285. [CrossRef] [PubMed]

8. Li, C.; Zheng, Z.; Jiang, J.; Jiang, W.; Lee, K.; Berthiaume, E.A.; Chen, E.C.; Culiat, C.T.; Zhou, Y.-H.; Zhang, X.; et al. Neural EGFL like 1 (Nell-1) regulates cartilage maturation through runt-related transcription factor 3-mediated indian hedgehog signaling. Am. J. Pathol. 2017, in press.

9. Chen, W.; Zhang, X.; Siu, R.K.; Chen, F.; Shen, J.; Zara, J.N.; Culiat, C.T.; Tetradis, S.; Ting, K.; Soo, C. Nfatc2 is a primary response gene of Nell-1 regulating chondrogenesis in ATDC5 cells. J. Bone Miner. Res. 2011, 26, 1230-1241. [CrossRef] [PubMed] 
10. Yoshida, C.A.; Yamamoto, H.; Fujita, T.; Furuichi, T.; Ito, K.; Inoue, K.; Yamana, K.; Zanma, A.; Takada, K.; Ito, Y.; et al. Runx2 and Runx3 are essential for chondrocyte maturation, and Runx2 regulates limb growth through induction of indian hedgehog. Genes Dev. 2004, 18, 952-963. [CrossRef] [PubMed]

11. Wuelling, M.; Vortkamp, A. Chondrocyte proliferation and differentiation. Endocr. Dev. 2011, 21, 1-11. [PubMed]

12. Chen, H.; Ghori-Javed, F.Y.; Rashid, H.; Adhami, M.D.; Serra, R.; Gutierrez, S.E.; Javed, A. Runx2 regulates endochondral ossification through control of chondrocyte proliferation and differentiation. J. Bone Miner. Res. 2014, 29, 2653-2665. [CrossRef] [PubMed]

13. Wigner, N.A.; Soung do, Y.; Einhorn, T.A.; Drissi, H.; Gerstenfeld, L.C. Functional role of Runx3 in the regulation of aggrecan expression during cartilage development. J. Cell. Physiol. 2013, 228, 2232-2242. [CrossRef] [PubMed]

14. Ting, K.; Vastardis, H.; Mulliken, J.B.; Soo, C.; Tieu, A.; Do, H.; Kwong, E.; Bertolami, C.N.; Kawamoto, H.; Kuroda, S.; et al. Human Nell-1 expressed in unilateral coronal synostosis. J. Bone Miner. Res. 1999, 14, 80-89. [CrossRef] [PubMed]

15. Zhang, X.; Kuroda, S.; Carpenter, D.; Nishimura, I.; Soo, C.; Moats, R.; Iida, K.; Wisner, E.; Hu, F.Y.; Miao, S.; et al. Craniosynostosis in transgenic mice overexpressing Nell-1. J. Clin. Investig. 2002, 110, 861-870. [CrossRef] [PubMed]

16. Zhang, X.; Carpenter, D.; Bokui, N.; Soo, C.; Miao, S.; Truong, T.; Wu, B.; Chen, I.; Vastardis, H.; Tanizawa, K.; et al. Overexpression of Nell-1, a craniosynostosis-associated gene, induces apoptosis in osteoblasts during craniofacial development. J. Bone Miner. Res. 2003, 18, 2126-2134. [CrossRef] [PubMed]

17. Zhang, X.; Zara, J.; Siu, R.K.; Ting, K.; Soo, C. The role of Nell-1, a growth factor associated with craniosynostosis, in promoting bone regeneration. J. Dent. Res. 2010, 89, 865-878. [CrossRef] [PubMed]

18. Zhang, X.; Ting, K.; Pathmanathan, D.; Ko, T.; Chen, W.; Chen, F.; Lee, H.; James, A.W.; Siu, R.K.; Shen, J.; et al. Calvarial cleidocraniodysplasia-like defects with enu-induced Nell-1 deficiency. J. Craniofac. Surg. 2012, 23, 61-66. [CrossRef] [PubMed]

19. Truong, T.; Zhang, X.; Pathmanathan, D.; Soo, C.; Ting, K. Craniosynostosis-associated gene Nell-1 is regulated by Runx2. J. Bone Miner. Res. 2007, 22, 7-18. [CrossRef] [PubMed]

20. Zhang, X.; Ting, K.; Bessette, C.M.; Culiat, C.T.; Sung, S.J.; Lee, H.; Chen, F.; Shen, J.; Wang, J.J.; Kuroda, S.; et al. Nell-1, a key functional mediator of Runx2, partially rescues calvarial defects in Runx $2^{+/-}$mice. J. Bone Miner. Res. 2011, 26, 777-791. [CrossRef] [PubMed]

21. James, A.W.; Shen, J.; Velasco, O.; Asatrian, G.; Chung, C.G.; Khadarian, K.; Zhang, Y.; Chang, L.; Goyal, R.; Zhang, X.; et al. Systemic administration of Nell-1, a Wnt/ $\beta$-catenin regulator, induces bone formation in osteoporotic mice via integrin $\beta 1$. Presented at The Annual American Society of Bone and Mineral Research Meeting, Baltimore, MD, USA, October 2013.

22. Kim, I.S.; Otto, F.; Zabel, B.; Mundlos, S. Regulation of chondrocyte differentiation by Cbfa1. Mech. Dev. 1999, 80, 159-170. [CrossRef]

23. Hasebe, A.; Nakamura, Y.; Tashima, H.; Takahashi, K.; Iijima, M.; Yoshimoto, N.; Ting, K.; Kuroda, S.; Niimi, T. The C-terminal region of NELL1 mediates osteoblastic cell adhesion through integrin $\alpha 3 \beta 1$. FEBS Lett. 2012, 586, 2500-2506. [CrossRef] [PubMed]

24. Shen, J.; James, A.W.; Chung, J.; Lee, K.; Zhang, J.B.; Ho, S.; Lee, K.S.; Kim, T.M.; Niimi, T.; Kuroda, S.; et al. Nell-1 promotes cell adhesion and differentiation via integrin $\beta 1$. J. Cell. Biochem. 2012, 113, 3620-3628. [CrossRef] [PubMed]

25. Ranger, A.M.; Gerstenfeld, L.C.; Wang, J.; Kon, T.; Bae, H.; Gravallese, E.M.; Glimcher, M.J.; Glimcher, L.H. The nuclear factor of activated T cells (NFAT) transcription factor Nfatp (Nfatc2) is a repressor of chondrogenesis. J. Exp. Med. 2000, 191, 9-22. [CrossRef] [PubMed]

26. Wang, J.; Gardner, B.M.; Lu, Q.; Rodova, M.; Woodbury, B.G.; Yost, J.G.; Roby, K.F.; Pinson, D.M.; Tawfik, O.; Anderson, H.C. Transcription factor NFAT1 deficiency causes osteoarthritis through dysfunction of adult articular chondrocytes. J. Pathol. 2009, 219, 163-172. [CrossRef] [PubMed]

27. Rodova, M.; Lu, Q.; Li, Y.; Woodbury, B.G.; Crist, J.D.; Gardner, B.M.; Yost, J.G.; Zhong, X.B.; Anderson, H.C.; Wang, J. Nfat1 regulates adult articular chondrocyte function through its age-dependent expression mediated by epigenetic histone methylation. J. Bone Miner. Res. 2011, 26, 1974-1986. [CrossRef] [PubMed]

28. Sohn, P.; Cox, M.; Chen, D.; Serra, R. Molecular profiling of the developing mouse axial skeleton: A role for Tgfbr2 in the development of the intervertebral disc. BMC Dev. Biol. 2010, 10, 29. [CrossRef] [PubMed] 
29. Zanotti, S.; Canalis, E. Notch suppresses nuclear factor of activated T cells (NFAT) transactivation and Nfatc1 expression in chondrocytes. Endocrinology 2013, 154, 762-772. [CrossRef] [PubMed]

30. Ge, X.P.; Tsang, K.; He, L.Z.; Garcia, R.A.; Ermann, J.; Mizoguchi, F.; Zhang, M.J.; Zhou, B.; Zhou, B.; Aliprantis, A.O. NFAT restricts osteochondroma formation from entheseal progenitors. JCI Insight 2016, 1, e86254. [CrossRef] [PubMed]

31. Greenblatt, M.B.; Ritter, S.Y.; Wright, J.; Tsang, K.; Hu, D.; Glimcher, L.H.; Aliprantis, A.O. NFATc1 and NFATc2 repress spontaneous osteoarthritis. Proc. Natl. Acad. Sci. USA 2013, 110, 19914-19919. [CrossRef] [PubMed]

32. Beier, F. NFATs are good for your cartilage. Osteoarthr. Cartil. 2014, 22, 893-895. [CrossRef] [PubMed]

33. Aliprantis, A.O.; Glimcher, L.H. NFATc1 in inflammatory and musculoskeletal conditions. Adv. Exp. Med. Biol. 2010, 658, 69-75. [PubMed]

34. Klingenhoff, A.; Frech, K.; Quandt, K.; Werner, T. Functional promoter modules can be defected by formal models independent of overall nucleotide sequence similarity. Bioinformatics 1999, 15, 180-186. [CrossRef] [PubMed]

35. Otto, F.; Thornell, A.P.; Crompton, T.; Denzel, A.; Gilmour, K.C.; Rosewell, I.R.; Stamp, G.W.; Beddington, R.S.; Mundlos, S.; Olsen, B.R.; et al. Cbfa1, a candidate gene for cleidocranial dysplasia syndrome, is essential for osteoblast differentiation and bone development. Cell 1997, 89, 765-771. [CrossRef]

36. Rinchik, E.M.; Carpenter, D.A.; Selby, P.B. A strategy for fine-structure functional analysis of a 6- to 11-centimorgan region of mouse chromosome 7 by high-efficiency mutagenesis. Proc. Natl. Acad. Sci. USA 1990, 87, 896-900. [CrossRef] [PubMed]

37. Rinchik, E.M.; Carpenter, D.A.; Johnson, D.K. Functional annotation of mammalian genomic DNA sequence by chemical mutagenesis: A fine-structure genetic mutation map of a 1- to 2-cm segment of mouse chromosome 7 corresponding to human chromosome 11p14-p15. Proc. Natl. Acad. Sci. USA 2002, 99, 844-849. [CrossRef] [PubMed]

38. Yao, Y.; Wang, Y. ATDC5: An excellent in vitro model cell line for skeletal development. J. Cell. Biochem. 2013, 114, 1223-1229. [CrossRef] [PubMed]

39. Livak, K.J.; Schmittgen, T.D. Analysis of relative gene expression data using real-time quantitative PCR and the $2^{-\Delta \Delta C T}$ method. Methods 2001, 25, 402-408. [CrossRef] [PubMed]

40. MacRae, V.E.; Davey, M.G.; McTeir, L.; Narisawa, S.; Yadav, M.C.; Millan, J.L.; Farquharson, C. Inhibition of phospho1 activity results in impaired skeletal mineralization during limb development of the chick. Bone 2010, 46, 1146-1155. [CrossRef] [PubMed] 